Revista Brasileira de Informática na Educação - RBIE

Brazilian Journal of Computers in Education

(ISSN online: 2317-6121; print: 1414-5685)

http://br-ie.org/pub/index.php/rbie

Submission: 01/Apr/2018;

Camera ready: 17/Jul/2018; $1^{\text {st }}$ round notif.: $28 / \mathrm{Jun} / 2018$; Edition review: 20/Aug/2018;
Available online: 01/Nov/2018; $\quad$ Published: 01/Jan/2019;

\title{
Um framework de classificação de complexidade para infográficos
}

\author{
Title: Complexity classification framework for infographics
}

\author{
Kamila Takayama Lyra \\ Universidade de São Paulo \\ kalyra_03@usp.br
}

Seiji Isotani

Universidade de São Paulo

sisotani@icmc.usp.br

\author{
Rachel Reis \\ Universidade de São Paulo \\ Universidade Federal de Viçosa \\ rachel.reis@usp.br
}

\author{
Wilmax Marreiro Cruz \\ Universidade de São Paulo \\ wilmcruz@icmc.usp.br
}

\begin{abstract}
Resumo
Os infográficos passaram a ser empregados como material de apoio ao ensino devido a sua natureza informativa. As evidências empíricas mostram que o uso desse formato de visualização afeta o aprendizado e o interesse dos alunos. No entanto, ainda é necessário fornecer maiores detalhes sobre os parâmetros que garantem os resultados positivos. Um desses parâmetros é complexidade dos infográficos. Logo, é preciso obter informações sobre o impacto de infográficos com diferentes níveis de complexidade no aprendizado. Observando a ausência de diretrizes que pudessem ser aplicadas para classificar a complexidade de infográficos, este trabalho propôs um framework que considera três dimensões (visual, verbal e conceitual) e o utiliza para pontuar infográficos, gerando uma medida de complexidade. Para avaliar o framework foi realizado um experimento controlado cujo objetivo foi verificar se a complexidade medida representa a real complexidade pro usuário. Analisando os resultados verificou-se que, de fato, os usuários aprenderam mais a partir de infográficos classificados como de baixa e média complexidade. Conclui-se que o fator complexidade do infográfico afeta o aprendizado e deve ser considerado por professores e criadores de conteúdo na decisão de se utilizar infográficos como materiais de aprendizagem.
\end{abstract}

Palavras-chave: Infográficos; Classificação; Complexidade; Aprendizado; Framework.

\begin{abstract}
Infographics have been used as learning materials due to their informative nature. Empirical evidence shows that this kind of visualization affects students' learning and interest. However, providing further details on which parameters ensure positive results is still required. An example of such parameter is the complexity of the infographics. Therefore, there is a need to obtain information on the impact of infographics of different levels of complexity in learning. Observing the lack of guidelines to classify the complexity of infographics, we propose a framework that considers three dimensions (i.e., visual, verbal and conceptual) to score infographics and, generate a complexity measure. We carried out a controlled experiment to evaluate the framework and verify if our complexity measure reflects the real perception of the users. Our results showed that users learned more from infographics classified as low and medium complexity. We conclude that the complexity of an infographic is a factor that affects learning and should be considered by teachers and content creators when deciding to use infographics as learning materials.
\end{abstract}

Keywords: Infographics; Classification; Complexity; Learning; Framework.

Cite as: Lyra, K. T., Reis, R., Cruz, W. M., \& Isotani, S. (2019). Complexity classification framework for infographics (Um framework de classificação de complexidade para infográficos). Brazilian Journal of Computers in Education (Revista Brasileira de Informática na Educação - RBIE), 27(1), 196-223. DOI: 10.5753/RBIE.2019.27.01.196. 


\section{Introdução}

O uso de visualizações de informação com o objetivo de mediar o aprendizado tem oferecido diversos benefícios para a aquisição e retenção de conhecimento (Zhang-Kennedy, Chiasson, \& Biddle, 2013). As visualizações têm o objetivo de representar e comunicar informações de maneira clara e eficiente utilizando, principalmente, meios gráficos. A representação visual da informação facilita a compreensão de relações e de padrões pelo cérebro humano. Sobretudo, as formas gráficas permitem relacionar dados e observar padrões que outras abordagens não possibilitam (Cleveland, 1994).

Diversos formatos de visualização são utilizados com o objetivo de facilitar o aprendizado. Dentre eles, um formato que tem ganhado popularidade no contexto educacional é o infográfico (contração do termo em inglês information graphic)(Lee \& Kim, 2016; Toth, 2013). Infográficos unem elementos de design a dados para ajudar a transmitir informações de modo objetivo (Smiciklas, 2012). A visualização gerada por um infográfico busca comunicar ideias ou informações complexas para um determinado público de maneira que essas informações sejam rapidamente compreendidas.

Devido a sua natureza informativa, os infográficos passaram a ser empregados como material de apoio ao ensino. As evidências empíricas mostram que o uso desse formato de visualização afeta o aprendizado e o interesse dos alunos (Diakopoulos, Kivran-swaine, \& Naaman, 2011; K. T. Lyra, Oliveira, et al., 2016). Lee \& Kim, 2016 relatam em seus experimentos que os infográficos aumentaram, principalmente, o engajamento dos alunos. Considerando a comparação do uso de infográficos com outros formatos de materiais de aprendizagem (texto puro e gráfico+texto), os infográficos demonstraram ser tão benéficos quanto os materiais tradicionais para o processo de aprendizagem (K. Lyra \& Isotani, 2017; K. T. Lyra, Oliveira, et al., 2016)

Considerando os trabalhos que investigam a real influência do formato infográfico no aprendizado (K. Lyra \& Isotani, 2017; Lee \& Kim, 2016), ainda é necessário fornecer maiores detalhes sobre os parâmetros que garantem os resultados positivos. Algumas investigações concluíram que os alunos que utilizaram infográficos aprenderam mais do que os alunos que utilizaram formatos de material de aprendizagem tradicionais (K. T. Lyra, Isotani, et al., 2016; Diakopoulos et al., 2011). Porém, nada foi dito sobre a variação na complexidade dos infográficos. Nesse contexto, surge a seguinte questão "os infográficos são adequados para qualquer quantidade e complexidade de informação que se deseja representar?”, ou seja, "a complexidade desse tipo de material pode influenciar no aprendizado e retenção de conhecimento?”. O processo de criação de infográficos com qualidade é custoso, pois depende de profissionais com conhecimentos específicos em, por exemplo, ilustração, design gráfico e redação. Logo, é preciso obter informações sobre o comportamento de infográficos com diferentes níveis de complexidade.

No intuito de levantar indícios para responder a esses questionamentos, é necessário classificar um conjunto de infográficos de acordo com sua complexidade. No entanto, não é possível classificar um infográfico apenas visualmente, pois, isso torna o processo de classificação demasiadamente subjetivo. Assim, foi realizada uma busca por frameworks ou diretrizes (guidelines) que pudessem ser aplicados para verificar a complexidade dos infográficos.

Não foram encontrados frameworks apropriados para a classificação de complexidade de 
infográficos. Apesar disso, os resultados serviram de base para definir as variáveis que precisam ser consideradas para classificar a complexidade de um infográfico e propor, então, um framework específico para visualização de informação do tipo infográfico. Nesse contexto, esse artigo tem como objetivo apresentar o processo de construção, aplicação e avaliação de um framework para classificar a complexidade de visualizações do tipo infográficos, até então, inédito na literatura.

Este artigo se divide nas seguintes seções: A seção 2 fundamenta os conceitos necessários para a compreensão desse trabalho, enquanto que a seção 3 discute os trabalhos relacionados com a classificação de complexidade de visualizações de informação. O método de construção e aplicação do framework de complexidade é apresentado na seção 4. A seção 5 descreve o design do experimento executado para avaliar o framework de complexidade. Por fim, as seções 6 e 7 descrevem, respectivamente, os resultados da avaliação e a conclusão do trabalho.

\section{Fundamentação Teórica}

\subsection{Visualização da Informação}

Inicialmente, o termo 'visualização' era utilizado para descrever representações de dados científicos que davam suporte ao compartilhamento de experiências(McCormick, DeFanti, \& Brown, 1987). Atualmente, o termo 'visualização de informação' (VI) é definido pela área de Ciência da Computação como uma tecnologia específica, ou seja, um meio e não um artefato final. Assim, Card, Mackinlay, \& Shneiderman, 1999 definem visualização de informação como o uso de representações visuais e computacionais de dados abstratos com o objetivo de aumentar a compreensão. Para Carr, 1999, VIs são especialmente importantes quando esse conjunto de dados abstratos é muito grande.

Segundo Freitas, Chubachi, Luzzardi, \& Cava, 2001, visualizações de informação são dados de um domínio representados graficamente de modo que a capacidade de percepção do leitor seja explorada permitindo que, além da interpretação, ele possa compreender e deduzir novas informações. O uso do computador na geração dessas representações visuais é a principal característica da definição (Chen, 2005). No entanto, Masud, Valsecchi, Ciuccarelli, Ricci, \& Caviglia, 2010 destacam que VI pode ser definida como um processo que deve considerar, além da tecnologia envolvida, os objetivos, o público alvo e o contexto para variar o artefato final.

Visualizações de informação podem ser utilizadas em vários contextos. No contexto educacional, vêm sendo empregadas com o propósito de beneficiar o aprendizado e aumentar a motivação (Naps et al., 2003). Por meio de uma série de experimentos, Mayer et al. (Mayer, Bove, Bryman, Mars, \& Tapangco, 1996; Mayer, 2003) oferecem fortes evidências de que integrar informações visuais ao material de aprendizagem em formato textual gera melhores resultados com relação a retenção do conhecimento. As pesquisas na área afirmam que as visualizações que ilustram as estruturas da informação contribuem para melhorar a capacidade dos alunos de lidar com a complexidade do assunto abordado (Cuevas, Fiore, \& Oser, 2002; Jonassen, Reeves, Hong, Harvey, \& Peters, 1997; Gyselinck \& Tardieu, 1999).

Outras pesquisas buscam explicar os motivos por trás dos benefícios do uso de visualizações para a aprendizagem. Larkin \& Simon, 1987 afirmaram que a eficiência no processamento das VIs 
está relacionada com o maior número de inferências proporcionadas durante a leitura. Enquanto que para Cox, 1999, elas ajudam a enxergar as relações abstratas entre os elementos.

Os dados publicados por pesquisas neurais relacionadas ao modo como um indivíduo processa informações fundamentam a escolha de visualizações na comunicação de ideias. O processamento de informação visual é responsável por ocupar grande parte da atividade cerebral (Burkhard, 2004), cerca de 50\% do cérebro é dedicado (direta ou indiretamente) às funções visuais (MIT News, 1996).

No entanto, uma visualização sozinha pode não ser suficiente para que um usuário a compreenda completamente. Assim, Sebrechts, 2005 ressalta a necessidade de complementar a visualização com dicas verbais para ajudar o usuário a explorar todas as informações. Dentre os tipos de visualização existentes, o tipo infográfico faz essa associação de imagens a textos com o objetivo de facilitar sua comunicação com o leitor.

\subsubsection{Infográficos}

Segundo Smiciklas, 2012, infográfico, ou gráfico de informação, é uma visualização que associa dados com design, com o objetivo de transmitir informações concisas a uma determinada audiência. Para Smiciklas, 2012, o potencial dessa visualização está na transformação de conceitos abstratos e complexos em conhecimento intuitivo e instântaneo. Na definição de Risch, 2008, infográficos são representações visuais de dados, informações ou conhecimento que podem usar símbolos para ilustrar ideias. De modo semelhante, o valor de um infográfico está na sua capacidade de dar suporte à geração de inferências sobre a relação entre conceitos.

Para alguns autores, infográficos podem ser vistos como textos ilustrados, realçando uma das características visuais mais marcantes desse tipo de visualização: o uso de ilustrações correspondentes às explanações textuais curtas e objetivas (Ribas, 2004). As ilustrações ajudam a decompor conceitos complexos dando apoio à assimilação do conteúdo, pois mostram outra perspectiva sobre a informação escrita. Quando comparada a documentos de texto, a associação de textos e imagens contribui para elevar a facilidade de aprendizagem, o nível de compreensão e o interesse no domínio (McLoud, 2000).

Não é essencial que um infográfico possua uma apresentação linear de informações, sendo assim, a leitura pode começar pelo centro e partir para qualquer direção. Essa característica não elimina a necessidade de uma estrutura com começo, meio e fim. $\mathrm{O}$ ponto inicial de leitura deve ser destacado por uma imagem principal ou fonte diferente, enquanto que o corpo apresenta equilíbrio entre as proporções de textos e imagens. Para Leturia, 1998, a estrutura obrigatória de um infográfico deve ser composta por título, texto, corpo e fonte. O título deve ser auto-explicativo, o texto e corpo apresentam as informações do infográfico e a fonte garante a veracidade do que está sendo representado. Desse modo, em um infográfico, o fluxo de leitura diferenciado não impede a compreensão da visualização. Além disso, um bom infográfico tem um público alvo bem definido, permitindo que apenas as informações essenciais sejam apresentadas. Em contrapartida, o uso de infográficos não está limitado à nenhuma área de conhecimento. Contanto que o objetivo seja transmitir conhecimento, os infográficos podem ilustrar amplamente qualquer domínio, desde áreas da ciência da natureza (e.g. química, biologia, física) até política e negócios.

As características dos infográficos os tornam versáteis e permitem que possam ser utilizados 
com diferentes objetivos, seja por meio impresso ou digital: fazer analogias, descrever processos e acontecimentos, resumir ou detalhar fenômenos da natureza, divulgar fatos ou descobertas, comparar produtos, entre outros (Ribas, 2004). Sobretudo, atualmente, os infográficos são utilizados com o propósito de atender a nova geração de leitores que, cada vez mais, busca obter conhecimento de maneira rápida e atrativa. Para atender tais necessidades, o infográfico associa textos e imagens para chamar a atenção do leitor e tornar a informação mais clara e compreensiva.

Neste trabalho um infográfico é definido como um tipo de visualização de informação que utiliza figuras para ilustrar ideias, gráficos para representar dados e curtas explicações textuais. Esses três componentes precisam estar associados à elementos de design, gerando uma apresentação visualmente agradável, quase que apelativa, dos conceitos e informações(K. T. Lyra, 2017). No entanto, para compreender esse trabalho é necessário que o leitor tenha em mente não apenas o conceito do que são infográficos, mas também o tipo de design empregado em um infográfico, pois uma visualização pode transmitir informações por meio de ilustrações, gráficos e textos mas o termo utilizado para referenciá-la não ser "infográfico".

A Figura 1 é um exemplo de visualização do tipo infográfico que apresenta como tema o consumo de água no planeta. Nela é possível notar o design que foi pensado para remeter ao tema água (a), o uso de elementos gráficos para representar dados (b), o uso de ilustrações (c) e de curtas descrições textuais complementando as informações (d).

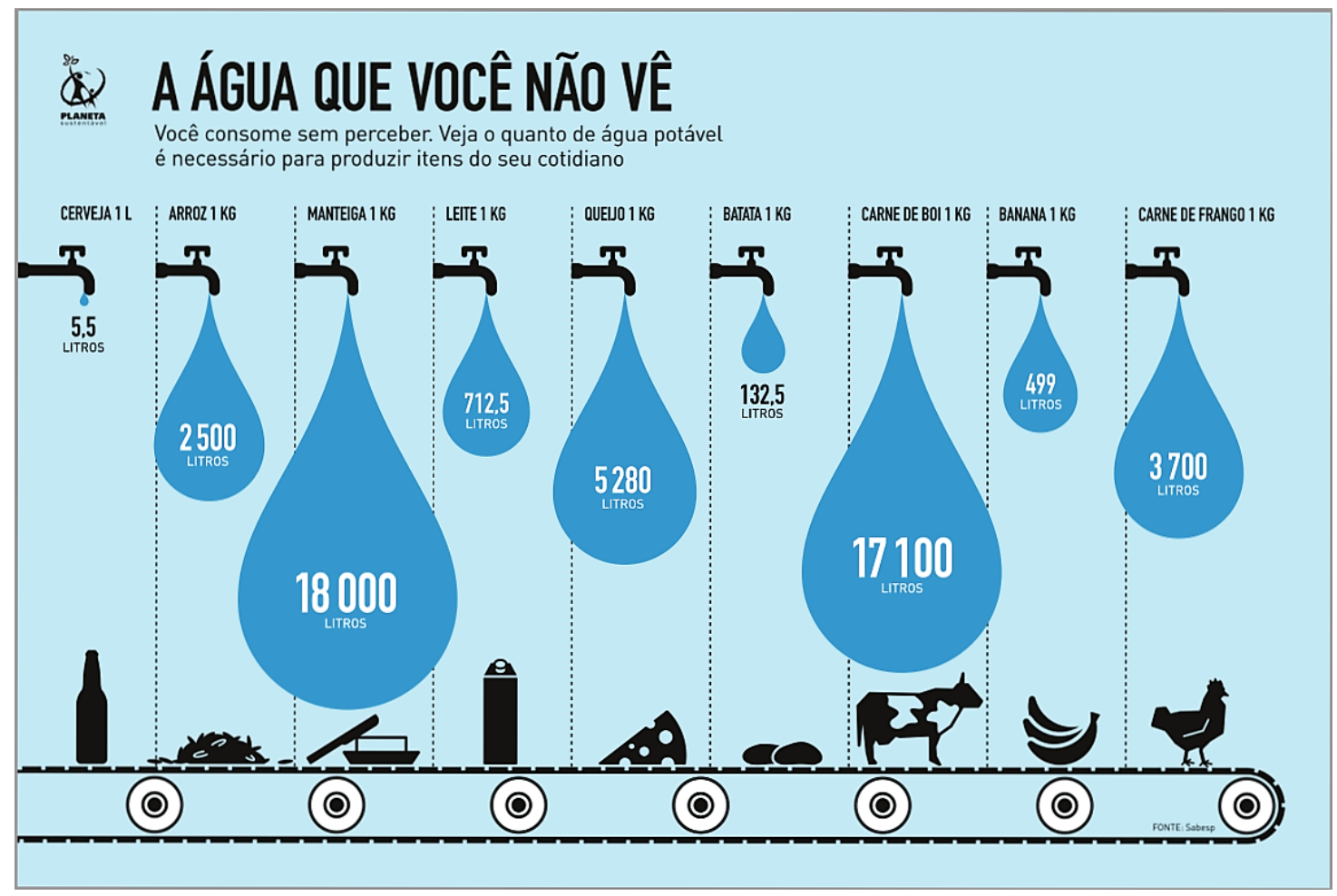

Figura 1: Exemplo de Infográfico 


\subsection{Teoria da Carga Cognitiva}

As visualizações do tipo infográfico tem como proposta a efetividade em transmitir informações concisas a uma determinada audiência(Smiciklas, 2012). Para a Teoria da Carga Cognitiva (TCC) de Sweler, essa comunicação de informações é mais efetiva quando o material está alinhado com a arquitetura cognitiva humana (Paas, Renkl, \& Sweller, 2004). Para Sweller, Van Merrienboer, \& Paas, 1998, a arquitetura cognitiva humana é composta de duas memórias: a memória de trabalho, ou de curto prazo, e a de longo prazo. A primeira é a responsável pelo pensamento ativo e armazenamento temporário das informações, processando informações visuais e verbais separadamente. No entanto, a memória de trabalho é limitada quanto ao número de informações que consegue processar simultaneamente. Ela pode armazenar cerca de sete elementos mas atuar apenas no intervalo entre dois e quatro elementos (Van Merrienboer \& Sweller, 2005). Assim, a memória de trabalho é um problema no processamento cognitivo humano em função da sua capacidade limitada de informações tratadas simultaneamente (Machado, Margarida, \& Tarouco, 2010).

Considerando essa limitação natural do ser humano em processar muitas informações ao mesmo tempo, a Teoria da Carga Cognitiva afirma que o aprendizado é mais eficaz quando o volume de informações em uma visualização respeita a carga suportada pela memória de trabalho (Van Merriënboer \& Sweller, 2010; Sweller et al., 1998). Assim, um infográfico eficiente precisa minimizar a carga cognitiva desnecessária e, ao invés disso, direcionar o processamento para o conteúdo que precisa ser informado. A partir disso, é possível compreender que a TCC considera algumas formas de carga cognitiva úteis e outras desnecessárias, são elas:

- Carga cognitiva intrínseca (intrinsic) - é o nível de complexidade inerente ao conteúdo a ser aprendido, logo, não pode ser mudada.

- Carga cognitiva irrelevante / estranha (extraneous) - causa processamento mental desnecessário de algo que não é importante para o aprendizado. Está ligada a presença de elementos irrelevantes e formas de apresentação confusas.

- Carga cognitiva relevante / natural (germane) - causa processamento que beneficia o aprendizado, também é imposta pela maneira como o conteúdo é apresentado mas de modo adequado ao conteúdo.

Uma visualização que foi formulada aplicando os princípios da TCC torna o aprendizado mais eficiente minimizando a carga cognitiva irrelevante e maximizando a carga cognitiva relevante (Paas et al., 2004). No caso de infográficos, a combinação de representações verbais e visuais é utilizada para contornar a limitação na memória de trabalho e diminuir a carga cognitiva irrelevante descrita por Sweller (Sweller et al., 1998). Na prática, deve existir equilíbrio entre a quantidade de estímulos verbais e visuais para que o leitor não desperdice recursos cognitivos tentando coordenar as duas fontes de informação.

Neste trabalho os conceitos propostos pela Teoria da Carga Cognitiva servem de alicerce teórico para a escolha das dimensões que compõem o framework de complexidade proposto. Assim, o cálculo de complexidade feito pelo framework traduz tanto as cargas cognitivas intrínseca, estranha e natural presentes nos infográficos. 


\section{Trabalhos Relacionados}

Considerando a proposta desse trabalho, foi realizada uma busca na literatura por frameworks ou diretrizes (guidelines) que pudessem ser aplicados para verificar a complexidade dos infográficos. Contudo, são raros os trabalhos nesta perspectiva. Logo, a revisão da literatura realizada decompôs os tópicos referentes ao tema e obteve trabalhos relacionados com a classificação de tipos de infográficos (Albers, 2015, 2014), tipos de VIs (Figueiras, 2013; Brehmer \& Munzner, 2013) e complexidade de VIs (Zhu, 2007; Zhu, Suo, \& Owen, 2007; Gärtner, Miksch, \& Carl-McGrath, 2002).

Albers, 2015 apresenta uma nomenclatura que classifica infográficos em quatro tipos: lista de tópicos, snapshots, informação plana e fluxo/processo de informação. Em seu primeiro trabalho o autor apresenta a nomenclatura e as características de cada tipo de infográfico (Albers, 2014), no entanto não demonstra o processo utilizado para chegar a essa classificação. É possível inferir que a classificação aplicada sobre uma coleção aleatória de infográficos é baseada em semelhança da visualização.

A classificação em tipos, baseada em semelhança, também é uma abordagem aplicada em visualizações de informação. Brehmer \& Munzner, 2013 propõe uma tipologia para classificar VIs de acordo com os diferentes objetivos da visualização e tarefas cognitivas que elas permitem ao usuário. No mesmo sentido, Figueiras, 2013 realizou uma análise comparativa de 200 visualizações que levou em consideração os elementos de narrativa, ordem de leitura, elementos visuais e elementos interativos. Essa análise resultou no levantamento de onze tipos diferentes de visualizações que não são mutuamente exclusivas. Observa-se que dentre os onze tipos de VIs propostos pela autora, não se encontra o tipo infográfico. Ou seja, o infográfico não foi considerado um tipo de VI. Ao invés disso, a autora coloca os infográficos no mesmo nível de VI, afirmando que sua classificação se aplica à eles também. A autora ressalta que os tipos propostos são úteis para identificar que elementos compõem uma boa visualização e menciona que escolher o tipo de visualização correto depende da complexidade dos dados, da audiência e da mídia de divulgação (Figueiras, 2013).

Apesar de apresentarem classificações para VIs, incluindo para infográficos, os trabalhos mencionados não abordam métricas que permitam classificar a complexidade de infográficos. Assim, as publicações descritas a seguir propõem parâmetros para classificar a complexidade de visualizações de informação. Zhu, 2007 discute e analisa a literatura no intuito de responder a pegunta: "como definir uma VI efetiva e como medir essa efetividade?". O autor considera que a eficiência da VI é dependente do usuário e deve ser medida de acordo com a facilidade do usuário em ler a visualização. Este trabalho não propõe uma métrica mas sim um conjunto de princípios para medir caracterizar a eficiência das visualizações que são: princípio da acurácia (correta relação entre os elementos visuais e os dados), princípio de utilidade (ajudar o usuário a atingir o objetivo de uma determinada tarefa) e o princípio de eficiência (reduzir a carga cognitiva de leitura).

Em um segundo trabalho, Zhu et al., 2007 propõem uma métrica para calcular a complexidade de VIs considerando fatores que influenciam na eficiência do processamento visual (integração visual, complexidade da interpretação dos atributos visuais e eficiência da busca visual). A métrica gerada por Zhu et al., 2007 representa a carga cognitiva estranha presente na visualização 
e é feita seguindo os passos: análise hierárquica das camadas da VI, relaciona as camadas em uma árvore de integração de complexidade, analisa a eficiência de se interpretar cada camada, e por fim analisa a eficiência da busca visual. Para validar o método os autores realizaram um estudo de caso utilizando um conjunto de visualizações relacionadas a segurança de computadores. Com a análise resultante foi possível identificar pontos de melhoria na visualização.

No mesmo sentido, Gärtner et al., 2002 apresentam uma métrica para medir a complexidade de VIs chamada de ViCo. A métrica analisa a legibilidade de visualizações de acordo com as particularidades de usuários e tarefas e permite uma comparação da complexidade relativa de um conjunto de visualizações para qualquer propósito. Os autores se apoiam na carência de trabalhos que considerem os chamados elementos e operações cognitivas ao analisar a complexidade de uma VI. Para Gärtner et al., 2002 sua proposta pode ser encarada como um algoritmo que se resume em: levantar os tipos de usuários, analisar as tarefas a serem executadas pelos tipo de usuários (e.g. encontrar um objeto, entender a diferença entre um objeto A e B), identificar as operações de leitura, escrita, comparação e cálculo necessárias para cada tarefa, e por fim, descrever esses elementos na forma de uma equação.

Ainda que os trabalhos discutidos tenham contribuições importantes para a área de visualização de informação, não foram encontrados trabalhos que apresentem soluções de classificação de complexidade específicas para visualizações do tipo infográficos. Logo, essa lacuna da literatura associada à necessidade de se conhecer a influência do fator complexidade na comunicação por meio de infográficos identifica uma oportunidade de investigação abordada por este trabalho.

\section{Método}

O framework proposto neste trabalho classifica a complexidade de visualizações do tipo infográficos por meio da avaliação de três dimensões de complexidade presentes nos infográficos: a complexidade visual, a complexidade textual e a complexidade conceitual. Essa seção descreve os fundamentos teóricos utilizados para a seleção dessas dimensões e construção do framework de complexidade. Além disso, apresenta um exemplo de aplicação em um infográfico.

\subsection{Complexidade Visual}

O conjunto de informações visuais transmitidas por um infográfico pode ser muito variado. A forma, a posição, a cor e outros atributos de cada elemento visual podem ter significados diferentes. Segundo a Teoria da Carga Cognitiva (Sweller, 1988), quanto mais informações associadas à forma de apresentação de um conteúdo, maior a carga cognitiva estranha. Quando isso ocorre, o aluno pode dedicar muito processamento à informação irrelevante e prejudicar o processamento do conteúdo e do conhecimento que realmente precisa ser adquirido. Assim, a complexidade visual de um infográfico pode ser dada pela demanda de carga cognitiva do leitor, tanto intrínseca quanto estranha.

A fim de obter um indicador da carga cognitiva associada à compreensão dos infográficos, foi utilizado o método proposto por Zhu et al., 2007 para análise da complexidade de visualizações de informação. Zhu et al., 2007 consideram um conjunto de fatores que influenciam no processa- 
mento eficiente da informação visual baseado nas teorias psicológicas da Carga Cognitiva (Clark, Nguyen, \& Sweller, 2011), de Gestalt (King \& Wertheimer, 2005) e Guided Visual Search (Wolfe \& Horowitz, 2004). O método é caracterizado pela análise hierárquica dos elementos visuais que são classificados em cinco camadas contidas umas nas outras, conforme ilustrado na Figura 2a. A menor camada é chamada de unidade visual. Em um infográfico uma unidade visual pode apresentar diferentes formatos, por exemplo: ponto, linha, forma 2D (figura, ícone), objeto 3D, texto, foto. Cada unidade visual é caracterizada por seis tipos de atributos (Bertin, 2011): posição, tamanho, forma, cor, orientação e textura. Quando um conjunto de unidades visuais são claramente percebidas como um grupo, segundo os princípios de proximidade, semelhança, fechamento, continuidade, simetria e pregnância, definidos por Gestalt (King \& Wertheimer, 2005), eles formam um padrão visual, que por sua vez, quando agrupados identificam um quadro visual. $\mathrm{O}$ conjunto de quadros visuais totais de uma visualização formam a área de trabalho existente em um infográfico.

Cada dado ou informação presente em um infográfico está mapeado a um atributo diferente de uma unidade visual. Por exemplo, na Figura $2 \mathrm{~b}$, o dado " 10 " está ligado ao atributo "forma"(meio círculo) representado no gráfico de pizza. Do mesmo modo, o dado "10 Tri" (primeiro trimestre) está ligado ao atributo "cor"(azul). Isso faz com que o leitor, além de precisar memorizar o mapeamento entre o dado e o atributo, também precise interpretar o valor desses atributos: "O que essa cor significa? O que essa forma representa?". Assim, o esforço mental para fazer essa interpretação é a principal fonte de carga cognitiva estranha.

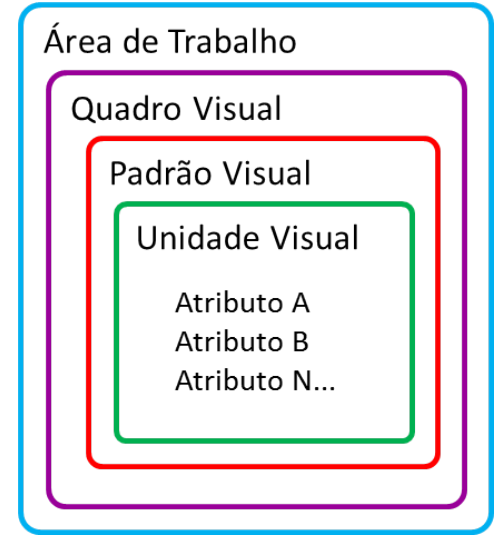

(a) Hierarquia de camadas em uma visualização.

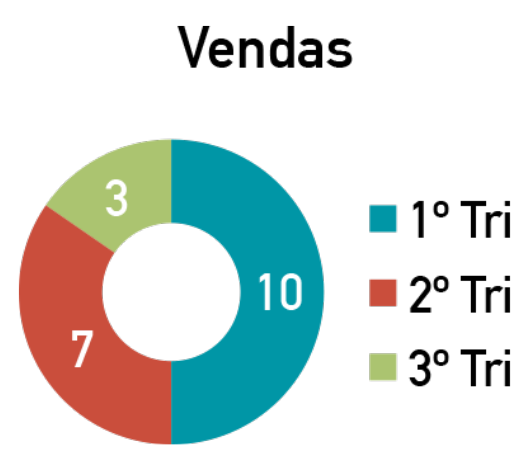

(b) Exemplo de mapeamento entre atributos e informações.

Figura 2: Elementos da classificação da complexidade visual.

É no conceito de carga cognitiva estranha que está baseada a classificação da complexidade visual. Para quantificar essa complexidade, cada atributo de cada unidade visual presente no infográfico recebe uma pontuação de complexidade que varia de 0 a 5 . Esse valor representa a dificuldade de se interpretar o atributo e o dado ligado a ele. Os critérios que estabelecem o grau de dificuldade foram baseados no estudo de Zhu et al., 2007 e são apresentados na Tabela 1.

Desse modo, para calcular a complexidade de uma unidade visual, deve-se somar os pontos de todos os atributos dessa unidade visual. Logo, a complexidade de um padrão visual é calculada pela soma das complexidades de todas suas unidades visuais (Figura 2a). Do mesmo 
Tabela 1: Valor de complexidade para atributos das unidades visuais.

\begin{tabular}{|l|l|}
\hline $\begin{array}{l}\text { Valor de } \\
\text { Complexi- } \\
\text { dade }\end{array}$ & Critério \\
\hline 5 & $\begin{array}{l}\text { Muito difícil de interpretar. Não há legenda. O leitor é obrigado a memorizar a } \\
\text { relação entre o valor do atributo e o valor do dado. }\end{array}$ \\
\hline 4 & Difícil de interpretar. O leitor precisa consultar a legenda frequentemente. \\
\hline 3 & $\begin{array}{l}\text { Um pouco difícil de interpretar. O leitor precisa consultar a legenda ocasional- } \\
\text { mente. }\end{array}$ \\
\hline 2 & Fácil de interpretar. O leitor só precisa consultar a legenda uma vez. \\
\hline 1 & Isso é de conhecimento comum. Não há necessidade de memorização ou legendas. \\
\hline 0 & Atributo sem dimensão. \\
\hline
\end{tabular}

modo, a complexidade de um quadro visual é obtida pela soma das complexidades de todos os padrões visuais dentro dele. Por fim, a complexidade final do infográficos é dada pela soma das complexidades de seus quadros visuais.

No intuito de exemplificar o cálculo da complexidade visual, será utilizado o infográfico "A água que você não vê" (Figura 3). O primeiro passo consiste em identificar todas as unidades visuais do infográfico, marcadas com o quadrado verde na Figura 3. Assim, cada ícone representando o produto (ex., galinha, banana, boi, batata, queijo, leite, manteiga, arroz e garrafa) é uma unidade visual (U). Do mesmo modo, cada torneira, cada gota, cada linha tracejada vertical separando os produtos, cada texto representando a quantidade de água (ex., 5,5 litros, 2500 litros, 18000 litros, etc.), cada texto acima das torneiras (ex., cerveja 1L, arroz $1 \mathrm{~kg}$, etc.). Outras unidades visuais desse infográfico são: a esteira abaixo dos produtos, o título do infográfico, a descrição do infográfico.

O conjunto de unidades visuais semelhantes agrupadas, como as gotas de água, as torneiras, os ícones representando os produtos, formam um padrão visual (P). Na Figura 3, os padrões foram destacados e numerados em vermelho. Outros padrões visuais que podem ser identificados nesse infográfico são: a esteira abaixo dos produtos (um padrão com apenas uma unidade visual), o conjunto de textos acima das torneiras (cerveja $1 \mathrm{~L}$, arroz $1 \mathrm{~kg}$, entre outros), o conjunto de linhas tracejadas verticais separando os produtos, o conjunto de textos representando a quantidade de água (5,5 litros, 18000 litros, entre outros), o conjunto de textos na parte superior do infográfico (título e descrição).

Finalmente, o conjunto de padrões visuais identificados na Figura 3 compõem o único quadro visual presente no infográfico (quadro 01), visto que não há separação nítida entre esse conjunto de padrões. Desse modo a área de trabalho do infográfico é composta apenas por esse quadro visual.

Após todos os elementos visuais da hierarquia serem identificados, o segundo passo consiste em atribuir os valores de complexidade aos atributos de cada unidade visual segundo os critérios da Tabela 1. A Tabela 2 exibe o valor de complexidade dado para cada atributo de cada unidade visual da Figura 3. A soma desses valores forma a complexidade da unidade visual. Por exemplo, a unidade visual U9 do padrão P7 (ícone galinha) somou um total de 3 pontos de complexidade, pois recebeu 2 pontos para o atributo "forma"e 1 para o atributo "posição". Assim, a Tabela 2 mostra que o padrão P7, formado pelos nove ícones dos produtos (U1 a U9), somou 32 pontos. 


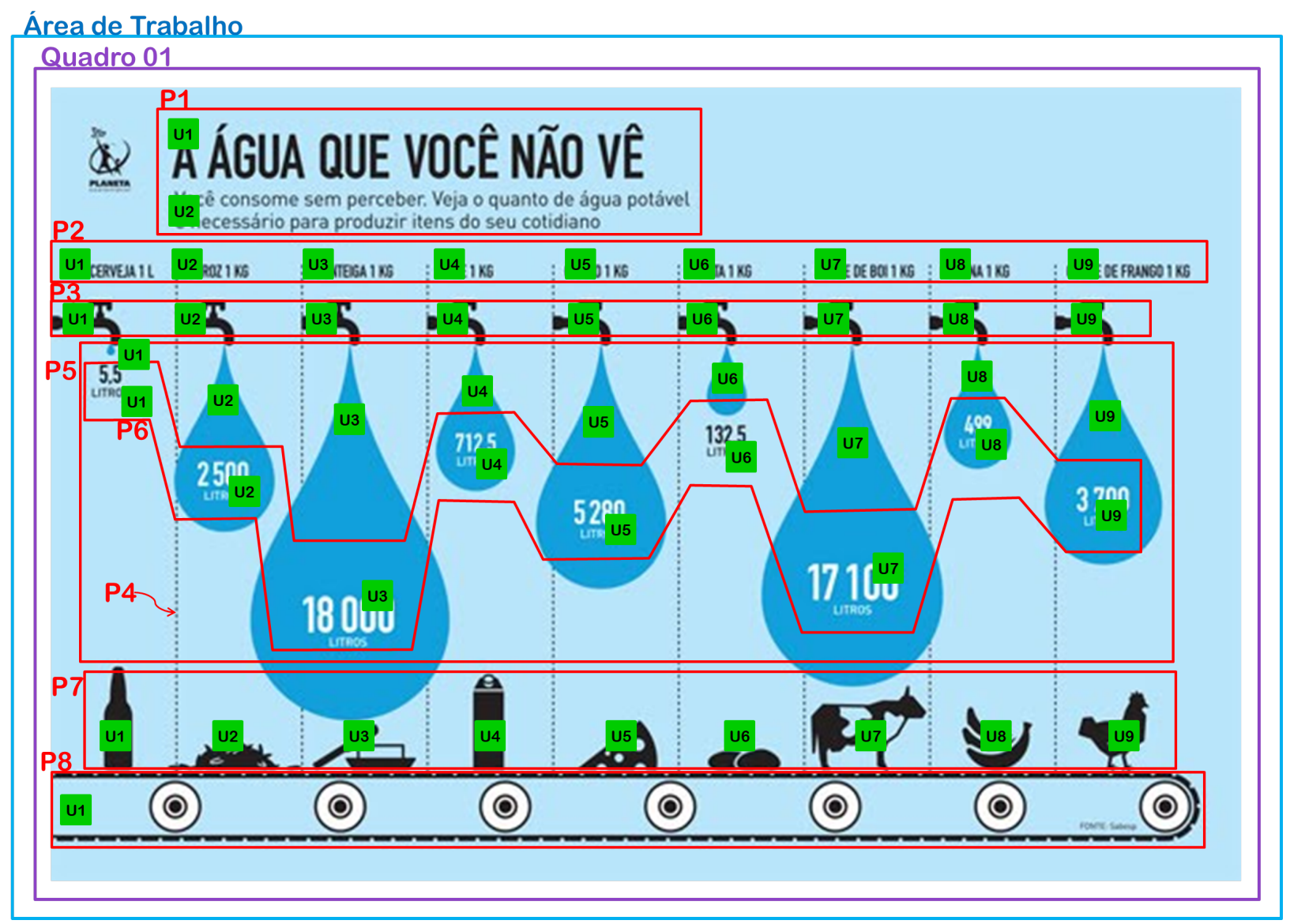

Figura 3: Exemplo de contagem das unidades visuais de um infográfico.

Esses pontos estão distribuídos entre todos os atributos das nove unidades visuais do padrão P7.

A soma das complexidades dos padrões P1 a P8 formam a complexidade do quadro visual Q1, que por sua vez resulta na complexidade visual do infográfico completo, visto que existe apenas esse quadro visual. Assim, a complexidade visual final do infográfico "A água que você não vê" resultou em 187 pontos.

\subsection{Complexidade Textual}

Com base no método de análise de complexidade visual definido por Zhu et al., 2007, neste trabalho o texto dissolvido no infográfico será tratado como uma unidade visual, visto que eles também interferem na percepção do infográfico. Cada conjunto de texto agrupado por uma caixa de texto, com fonte e cores semelhantes, foi contabilizado como uma unidade visual e o valor para seu atributo "forma"foi fixado no valor 1. No entanto, não podemos considerar um texto apenas como uma unidade de informação visual, é necessário também considerar a complexidade de leitura das palavras e frases nele contidas. Dessa forma, foi preciso associar o método de análise de complexidade visual a um método capaz de medir a complexidade textual presente no infográfico. Na literatura, esses métodos são chamados de teste de legibilidade (readability test). 
Tabela 2: Pontuação de complexidade visual para o infográfico "A água que você não vê".

\begin{tabular}{|c|c|c|c|c|c|c|c|c|c|c|c|}
\hline \multirow{2}{*}{\multicolumn{2}{|c|}{ Quadro / Valor }} & \multirow{2}{*}{\multicolumn{2}{|c|}{ Padrão / Valor }} & \multirow{2}{*}{\multicolumn{2}{|c|}{ Unidade / Valor }} & \multicolumn{6}{|c|}{ Atributos } \\
\hline & & & & & & cor & forma & posição & orientação & tamanho & textura \\
\hline \multirow{17}{*}{ Q1 } & \multirow[t]{17}{*}{ 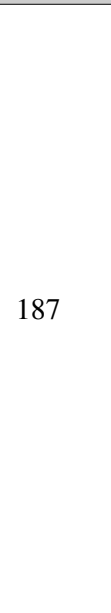 } & \multirow{2}{*}{ P1 - Título e texto } & \multirow{2}{*}{8} & U1 & 4 & 0 & 1 & 1 & 1 & 1 & 0 \\
\hline & & & & $\mathrm{U} 2$ & 4 & 0 & 1 & 1 & 1 & 1 & 0 \\
\hline & & P2 - Legenda dos produtos & 18 & U1 - U9 & 18 & 0 & 1 & 1 & 0 & 0 & 0 \\
\hline & & P3 - Torneiras & 18 & U1 - U9 & 18 & 0 & 2 & 0 & 0 & 0 & 0 \\
\hline & & P4 - Linhas & 0 & U1 - U8 & 0 & 0 & 0 & 0 & 0 & 0 & 0 \\
\hline & & P5 - Gotas & 63 & U1 - U9 & 63 & 1 & 2 & 1 & 0 & 3 & 0 \\
\hline & & P6 - Números & 45 & U1 - U9 & 45 & 0 & 1 & 1 & 0 & 3 & 0 \\
\hline & & \multirow{9}{*}{ P7 - Produtos } & \multirow{9}{*}{32} & U1 & 3 & 0 & 2 & 1 & 0 & 0 & 0 \\
\hline & & & & $\mathrm{U} 2$ & 5 & 0 & 4 & 1 & 0 & 0 & 0 \\
\hline & & & & U3 & 4 & 0 & 3 & 1 & 0 & 0 & 0 \\
\hline & & & & $\mathrm{U} 4$ & 4 & 0 & 3 & 1 & 0 & 0 & 0 \\
\hline & & & & U5 & 3 & 0 & 2 & 1 & 0 & 0 & 0 \\
\hline & & & & U6 & 5 & 0 & 4 & 1 & 0 & 0 & 0 \\
\hline & & & & U7 & 2 & 0 & 1 & 1 & 0 & 0 & 0 \\
\hline & & & & U8 & 3 & 0 & 2 & 1 & 0 & 0 & 0 \\
\hline & & & & U9 & 3 & 0 & 2 & 1 & 0 & 0 & 0 \\
\hline & & P8 - Esteira & 3 & U1 & 3 & 0 & 2 & 1 & 0 & 0 & 0 \\
\hline
\end{tabular}

Existem várias abordagens diferentes para medir a legibilidade de um texto (Schwarm \& Ostendorf, 2005; Collins-Thompson \& Callan, 2004; Stenner, 1996; Kincaid, Fishburne Jr, Rogers, \& Chissom, 1975; Fry, 1968; Dale \& Chall, 1948; Flesch, 1948). Neste trabalho optamos por utilizar o teste de "Facilidade de Leitura de Flesch" (Flesch Reading Ease - FRE)(Flesch, 1948), que é um teste consolidado, popular e simples de ser aplicado, pois não exige nenhuma ferramenta, além de possuir uma fórmula adaptada ao idioma português (português-BR). FRE é o

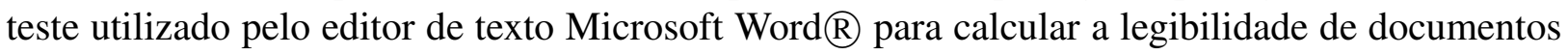
de texto.

A fórmula leva em consideração o número de sílabas, de palavras e de frases em um texto. O resultado é dado em uma escala com valores de 0 a 100, sendo que, quanto mais alto o valor, mais fácil é a leitura do texto. A fórmula para o idioma inglês é dada por:

$$
\text { Readability }=206,835-(1,015 \times A S L)-(84,6 \times A S W)
$$

Para o idioma português a fórmula é acrescida de 42 pontos que, de acordo com Martins, Ghiraldelo, Nunes, \& Júnior, 1996, é, na média, o número que diferencia textos no idioma inglês de textos no idioma português.

$$
\text { Legibilidade }=248,835-(1,015 \times A S L)-(84,6 \times A S W)
$$

Onde: ASL é o total de palavras no texto dividido pelo total de frases; ASW é dado pelo total de sílabas dividido pelo total de palavras. Os valores desse índice variam entre 100-75 (muito fácil), 75-50 (fácil), 50-25 (difícil) e 25-0 (muito difícil), que correspondem, respectivamente, às séries da educação primária ( $1^{\mathrm{a}}-4^{\mathrm{a}}$ (muito fácil) e $5^{\mathrm{a}}-8^{\mathrm{a}}$ (fácil)), secundária $\left(1^{\mathrm{o}}-3^{\mathrm{o}}\right.$ (difícil)) e ensino superior (muito difícil).

A título de exemplo, a fórmula de FRE será aplicada para calcular a complexidade textual do infográfico "A água que você não vê" (Figura 1). O primeiro passo é contar o número de palavras (24), o número de sílabas (48) e o número de frases (3) no texto. Como regra são considerados apenas títulos e parágrafos completos de texto, ou seja, legendas, logos e referências não são 
contabilizados. Em seguida, os valores são colocados na fórmula e é calculada a complexidade textual. Desse modo, o valor resultante para o infográfico "A água que você não vê" foi $\mathbf{7 1 , 5 1 5}$, colocando o infográfico na categoria "fácil" e adequado para leitura de alunos de $5^{\mathrm{a}}$ à $8^{\mathrm{a}}$ série.

$$
\begin{aligned}
& \text { Legibilidade }_{(\text {info_agua) }}=248,835-(1,015 \times(24 \div 3))-(84,6 \times(48 \div 24)) \\
& \text { Legibilidade }_{(\text {info_agua) }}=71,515
\end{aligned}
$$

\subsection{Complexidade Conceitual}

Além de considerar a carga cognitiva imposta pelos elementos visuais e pelos elementos textuais do infográfico, também é necessário considerar o processamento dos conceitos presentes no material. Alguns estudos consideram que quatro elementos processados simultaneamente é o limite ideal para promover processamento efetivo (Baddeley, 1994; Cowan, 2010; Halford, Andrews, \& Jensen, 1998). No entanto, Halford, Wilson, \& Phillips, 1998 afirmaram que a capacidade de processamento humana não deve ser definida de acordo com o número de itens que ocupam a memória de trabalho, mas sim de acordo com a complexidade das relações que podem ser processadas em paralelo. Assim, o trabalho de Halforf (Halford, Wilson, \& Phillips, 1998; Andrews, Halford, Bunch, Bowden, \& Jones, 2003; Andrews \& Halford, 2002) propõe a Teoria da Complexidade Relacional (Relational Complexity Theory - RCT) como método para quantificar a complexidade de informações.

Para a RCT, a complexidade de uma relação é dada pelo número de argumentos que ela contém. Assim, as relações podem ser unárias, binárias, ternárias, quaternárias, e assim por diante. Uma relação classificada como binária possui dois argumentos. Por exemplo, a relação "maior que" compreende dois argumentos, uma entidade maior e outra menor. As relações são representadas formalmente por: relação(argumento1, argumento2). Desse modo, a relação "maior que" seria representada por maior-que(argumento1, argumento2), podendo conter várias instâncias diferentes como maior-que(elefante, rato), maior-que(ônibus, bicicleta).

A RCT se baseia no limite de quatro elementos que podem ser mantidos na memória de trabalho para afirmar que o processamento humano também fica restrito a processar relações de no máximo quatro argumentos (relações quaternárias). Assim, um dos pressupostos da RCT é que, para diminuir a complexidade conceitual de um material, as relações maiores devem ser quebradas em relações menores. Por exemplo, a frase "Maria joga bola no parque" é classificada como uma relação ternária, sendo representada por jogar(pessoa, jogo, lugar). A relação ternária possui complexidade maior do que duas relações binária como jogar(pessoa, jogo) e é-jogado-em(jogo, lugar).

Apesar da RCT oferecer alicerce teórico para identificar as relações e qual o grau de complexidade entre elas, não é fornecida nenhuma medida quantitativa para as complexidades. Com o intuito de obter uma variável numérica que possa ser adicionada às medidas de Complexidade Visual e Textual, nós propomos valores para as complexidades relacionais, com base nos pressupostos da RCT. Segundo a RCT: $r\left(x_{1}\right)<r\left(x_{1}, x_{2}\right)<r\left(x_{1}, x_{2}, x_{3}\right)<r\left(x_{1}, x_{2}, x_{3}, x_{4}\right)$, logo, são propostos os seguintes valores numéricos, baseados na menor unidade, para cada grau de relação:

- $r\left(x_{1}\right)=1$; 
- $r\left(x_{1}, x_{2}\right)=3$;

- $r\left(x_{1}, x_{2}, x_{3}\right)=5$;

- $r\left(x_{1}, x_{2}, x_{3}, x_{4}\right)=7$

Esse valores foram planejados para cumprir a premissa de que poucas relações com muitos argumentos são mais complexas do que várias relações com poucos argumentos, desde que o número de argumentos nesse conjunto de relações menores não ultrapasse o número de argumentos nas relações maiores. Alguns exemplos podem ser vistos na Tabela 3. A primeira linha mostra que uma relação binária, que recebeu o valor 3, é maior do que duas relações unárias que recebem o valor 1 cada uma.

Tabela 3: Exemplo de valores quantitativos para complexidade conceitual.

\begin{tabular}{|c|c|}
\hline RCT & Medida Quantitativa \\
\hline$r\left(x_{1}, x_{2}\right)>\left(x_{1}\right)+r\left(x_{1}\right)$ & $3>1+1$ \\
\hline$r\left(x_{1}, x_{2}, x_{3}\right)>\left(x_{1}\right)+r\left(x_{1}, x_{2}\right)$ & $5>1+3$ \\
\hline$r\left(x_{1}, x_{2}, x_{3}, x_{4}\right)>\left(x_{1}, x_{2}\right)+r\left(x_{1}, x_{2}\right)$ & $7>3+3$ \\
\hline$r\left(x_{1}, x_{2}, x_{3}, x_{4}\right)>\left(x_{1}, x_{2}, x_{3}\right)+r\left(x_{1}\right)$ & $7>5+1$ \\
\hline
\end{tabular}

Tendo como exemplo o infográfico "A água que você não vê" (Figura 1) é possível determinar o valor da complexidade conceitual do infográfico utilizando as medidas propostas para a Teoria de Complexidade Relacional. O primeiro passo é identificar as informações (insigths) presentes no infográfico. No caso do infográfico "A água que você não vê" foi possível abstrair apenas uma informação que se repete em todo o infográfico: "quantidade de água necessária para produzir um item". O segundo passo é transformar as informações extraídas do infográfico em relações. Assim, foram identificadas duas relações: produz(água, item) e quantidade( $x)$ onde $x$ pode ser tanto água como item. O último passo é utilizar os valores propostos para as complexidades relacionais para quantificar as relações como exibido na Tabela 4. Assim, a complexidade conceitual final do infográfico é 4.

Tabela 4: Exemplo de complexidade conceitual para o infográfico "A água que você não vê".

\begin{tabular}{|l|l|c|}
\hline Informação & Relações & Valor \\
\hline $\begin{array}{l}\text { Quantidade de água necessária para pro- } \\
\text { duzir um item }\end{array}$ & $\begin{array}{l}\text { quantidade }(\mathrm{x})+\text { produz(água, item); } \mathrm{x}= \\
\text { água, item }\}\end{array}$ & $1+3=4$ \\
\hline
\end{tabular}

\subsection{Complexidade do Infográfico}

Cada dimensão de complexidade do framework foi proposta considerando as características gerais dos infográficos de unir imagens a gráficos e curtas explicações textuais. Assim, a união das dimensões de complexidades (visual, verbal e conceitual) formam a complexidade final do infográfico representada pela fórmula a seguir. A complexidade textual precisa ser subtraída de 100 visto que o teste (Flesch Reading Ease - FRE) resulta em um valor inverso, ou seja, quanto mais alto o valor mais fácil é a leitura do texto. Assim, para o infográfico "A água que você não vê" (Figura 1) temos a complexidade final de $\mathbf{2 1 9 , 4 8 5}$ pontos. 


$$
\begin{aligned}
& \text { Complexidade }_{(\mathrm{i})}=\text { CVisual }_{(\mathrm{i})}+\left(100-\text { CTextual }_{(\mathrm{i})}\right)+\text { CConceitual }_{(\mathrm{i})} \\
& 219,485=187+(100-71,515)+4
\end{aligned}
$$

\section{Avaliação do Framework de Complexidade}

A fim de avaliar as métricas e dimensões propostas para a classificação de complexidade de infográficos, foi realizado um experimento controlado. O objetivo geral do experimento foi verificar se a complexidade calculada pelo framework tem relação com a real complexidade do infográfico. No intuito de alcançar esse objetivo, foram selecionadas duas variáveis de investigação: aprendizado e tempo. Dada a proposição de que infográficos menos complexos são capazes de transmitir seu conteúdo de forma mais eficiente(K. T. Lyra, Oliveira, et al., 2016), espera-se que quanto maior o aprendizado a partir do infográfico, menor seja sua complexidade. Assim, o primeiro conjunto de hipóteses verifica se o aprendizado por meio de infográficos é afetado pela complexidade da visualização apresentada:

- Hipótese Nula: Não existe diferença entre o aprendizado por meio de infográficos com baixa, média ou alta complexidade.

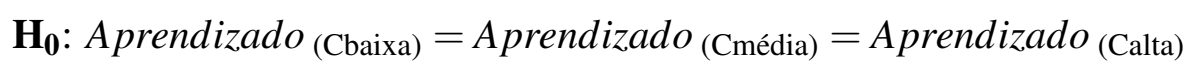

- Hipótese Alternativa: Existe diferença entre o aprendizado por meio de infográficos com baixa, média ou alta complexidade.

$$
\mathbf{H}_{\mathbf{1}} \text { : } \text { Aprendizado }_{\text {(Cbaixa) }} \neq \text { Aprendizado }_{(\text {Cmédia) }} \neq \text { Aprendizado }_{\text {(Calta) }}
$$

Do mesmo modo, espera-se que o tempo seja menor para um leitor analisar infográficos classificados como de baixa complexidade. Logo, também é importante observar a variável tempo de estudo dos infográficos, originando o segundo conjunto de hipóteses do experimento:

- Hipótese Nula: Não existe diferença entre o tempo de estudo de infográficos com baixa, média ou alta complexidade.

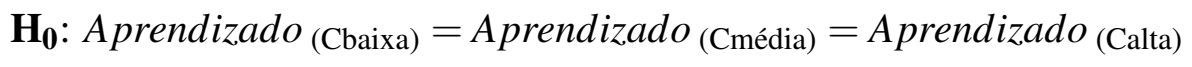

- Hipótese Alternativa: Existe diferença entre o tempo de estudo de infográficos com baixa, média ou alta complexidade.

$$
\mathbf{H}_{\mathbf{1}} \text { : } \text { Aprendizado }_{\text {(Cbaixa) }} \neq \text { Aprendizado }_{\text {(Cmédia) }} \neq \text { Aprendizado }_{\text {(Calta) }}
$$

\subsection{Instrumentos}

\subsubsection{Seleção dos Infográficos}

Uma amostra real de infográficos foi utilizada para verificar a capacidade do framework de categorizar os infográficos em níveis de complexidade. Nesse amostra foram selecionados 15 infográficos disponíveis na internet, encontrados por meio de uma busca simples por imagem no sistema 
de busca da Google ${ }^{1}$ utilizando o termo genérico "infográfico". Esse conjunto inicial foi escolhido primeiramente com base na apresentação visual que é característica dos infográficos (veja Seção 2.1.1), pelo uso da língua portuguesa (português-BR) e pela disponibilidade de download. Em uma segunda análise foram descartados os infográficos com baixa resolução e foram removidos infográficos com temas muito específicos como química e tecnologia. Permaneceram apenas infográficos com temas suficientemente genéricos, considerados de conhecimento comum.

Por fim, oframework com as dimensões propostas foi aplicado para pontuar a complexidade dos 15 infográficos. A aplicação foi feita por três pesquisadores que trabalharam em conjunto e simultaneamente nos 15 infográficos. Considerando a quantidade de infográficos e que a pontuação de cada dimensão é uma tarefa custosa, optou-se por especializar cada pesquisador em uma das dimensões de complexidade (visual, verbal e conceitual). Logo, cada pesquisador ficou responsável por pontuar uma dimensão da complexidade dos infográficos, segundo os critérios propostos no framework, e tendo os colegas como fonte de consulta e discussão em caso de dúvidas. Apenas a complexidade visual foi revisada por pares visto a subjetividade de pontuar a dificuldade de interpretação de cada atributo (Tabela 1).

As complexidades foram somadas resultando em um único valor para cada infográfico. Os infográficos em formato PNG e JPEG estão disponíveis no LabPackage do experimento em http:// kamilalyra.github.io/Experimento-Infograficos/.

\subsubsection{Questionários de conhecimento}

Para ser utilizado como ferramenta na coleta de dados sobre aprendizado foi desenvolvido um questionário de conhecimento referente às informações presentes infográficos utilizados.

O questionário é composto de 45 questões formuladas com base no conteúdo dos 15 infográficos selecionados, logo, para cada infográfico foram elaboradas três perguntas objetivas (i.e. múltipla escolha) com quatro opções de respostas, sendo uma a resposta correta e duas são alternativas erradas, não necessariamente apresentadas nessa ordem. A última alternativa para todas as questões é sempre a opção "Não sei". Essa alternativa foi utilizada como estratégia para desencorajar o "chute" (i.e. selecionar uma alternativa sem saber realmente a resposta da questão). Desse modo, espera-se nos resultados dos experimentos menor probabilidade de ocorrerem falsos acertos, ou seja, casos em que o aluno não sabe a resposta mas acerta por meio do "chute".

As aplicações do questionário foram espaçadas em sete dias para evitar o efeito de memorização das questões. Além disso, o questionário foi reescrito de três formas, usando vocabulários diferentes, cada forma foi aplicada em uma fase diferente do experimento.

Outro tipo de questão criada para o experimento mas sem o objetivo inicial de medir aprendizado é a questão-tema. A questão-tema é aplicada entre um infográfico e outro para evitar que os sujeitos simplesmente passem pelos materiais sem uma leitura adequada. Foram formuladas 15 questões-tema, uma para cada infográfico, sendo que a pergunta é sempre a mesma: "Qual o tema para o infográfico anterior?".

Os questionários de conhecimento com 45 questões em três formas diferentes e as 15 questões-tema podem ser encontrados na página do LabPackage do experimento, disponível em

\footnotetext{
${ }^{1}$ www.google.com.br
} 
http://kamilalyra.github.io/Experimento-Infograficos/index.html.

\subsection{Seleção dos sujeitos}

A generalização dos resultados de um experimento está diretamente relacionada com a escolha dos sujeitos. Para isso, a amostra selecionada deve ser representativa para a população alvo do experimento (Wohlin et al., 2012). Tendo em vista que infográficos são um tipo de visualização de informação que combina diferentes formatos de materiais de aprendizagem (textos, gráficos, ilustrações) é necessário que o leitor tenha capacidade de interpretar as três formas de modo holístico. No entanto, a habilidade de ler e compreender múltiplas fontes de informação é característica de leitores adultos (Hegarty, Carpenter, \& Just, 1991). É conhecido que jovens leitores têm a tendência de observar um componente isolado de uma visualização ao invés de considerar a visualização como um todo (Gerber, Boulton-Lewis, \& Bruce, 1995). Nesse sentido, a população alvo foi definida como alunos em nível de graduação para garantir a habilidade de interpretação dos infográficos.

A escolha da amostra de sujeitos para o experimento foi baseada em conveniência, caracterizando uma amostra não-probabilística, em que a probabilidade de se selecionar cada sujeito da amostra não é conhecida. Foi aproveitada a proximidade com os alunos da graduação da Universidade de São Paulo, campus São Carlos. Assim, ocorreram duas execuções do experimento final com as mesmas configurações. A primeira execução ocorreu em março de 2016 e contou com 58 alunos no primeiro semestre do curso de Engenharia de Computação. A segunda execução ocorreu em maio de 2016 e teve como sujeitos 44 alunos do curso de Bacharelado em Sistemas de Informação.

\subsection{Design Experimental}

A coleta de dados foi realizada por meio de um sistema online desenvolvido para aplicar os questionários de conhecimento, exibir os infográficos para os alunos e gravar os dados de tempo(K. T. Lyra, 2017). A configuração do experimento conta com três fases distribuídas ao longo de três ou mais semanas: Fase A (Pré-teste), Fase B (Intervenção e Pós-teste) e Fase C (Teste de Retenção). O tempo entre uma fase e outra foi de uma semana.

Todas as fases foram realizadas em um laboratório de informática, onde os sujeitos cumpriram todas as atividades individualmente e pelo computador. Ao chegarem, os sujeitos já encontravam os computadores ligados, com o navegador aberto na página referente a fase do experimento. A seguir serão descritas as atividades que compõem cada fase do experimento. $\mathrm{O}$ fluxo das atividades do experimento está ilustrado na Figura 4.

Fase A (Pré-teste): Primeiramente, os sujeitos receberam uma breve descrição oral sobre os objetivos da atividade. Em seguida, foi dada a permissão para realização do cadastro e login no sistema. A primeira atividade consistiu em responder as 45 questões do questionário de conhecimento com o objetivo de mensurar seus conhecimentos prévios. Dessa maneira, é possível comparar a diferença de conhecimento dos sujeitos entre as Fases A e B, ou seja, antes e depois da interação com os infográficos. A condução foi feita por dois especialistas que interferiram apenas para lembrar que os sujeitos não poderiam interagir entre si ou sair da página do sistema online de 
experimentação.

Fase B (Intervenção e Pós-teste): Nesta fase, ao efetuar o login no sistema o sujeito inicia a interação com os 15 infográficos em ordem aleatória gerada pelo sistema. Após a visualização de um infográfico, o sujeito responde à uma questão-tema (descrito na Seção 5.1.2) referente ao material visto. Esse fluxo se repete por 15 vezes, até que o aluno visualize os 15 materiais e responda suas 15 questões-tema. O sistema online grava o tempo que cada aluno levou visualizando cada infográfico.

Após a interação com os infográficos, os alunos responderam a um novo questionário de conhecimento, que identifica o conhecimento logo após a interação com os infográficos. A condução da Fase B foi feita por três especialistas que orientaram os sujeitos a não interagirem entre si ou sair da página do sistema experimentação.

Fase C (Teste de Retenção): Na última fase do experimento, os alunos responderam ao questionário de conhecimento para avaliar o quanto eles retiveram de conhecimento sete dias após a interação com os infográficos. Essa fase foi conduzida por apenas um especialista.

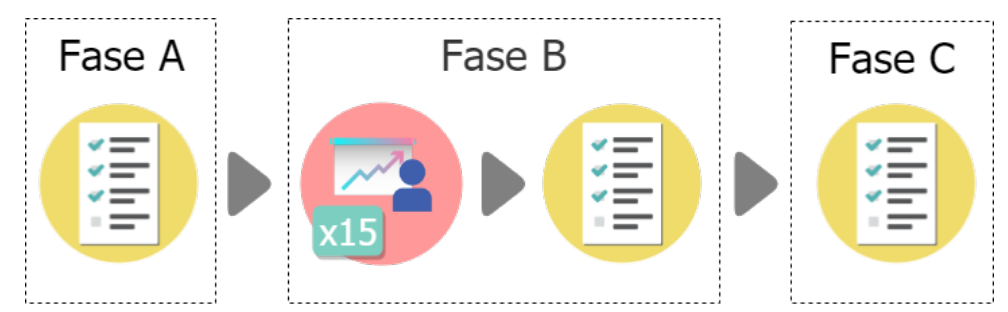

Figura 4: Atividades executadas em cada fase do experimento.

\section{Resultados}

Após a execução das três fases do experimento, foi dado início à verificação e análise dos dados. Para realizar as análises, foi utilizado o software estatístico SPSS $^{2}$. A análise de dados exibe primeiramente a estatística descritiva que apresenta as médias e medidas de dispersão para as variáveis aprendizado e tempo. Em seguida, são discutidos os Testes das Hipóteses definidos na Seção 5 .

As comparações realizadas nesta seção analisam as diferenças de aprendizado e tempo entre os infográficos de baixa, média e alta complexidade. A complexidade dos 15 infográficos foi calculada utilizando o framework proposto e descrito na Seção 4. Para a amostra de infográficos utilizada, o infográfico de complexidade mais baixa obteve 136 pontos, enquanto que o infográfico de complexidade mais alta obteve 1856 pontos. Para simplificar a análise foram criadas categorias de complexidade. Assim, os 5 infográficos com menor valor foram considerados de baixa complexidade (136 a 398 pontos), os 5 infográficos com maior valor foram considerados de alta complexidade (1500 a 1856 pontos) e os 5 infográficos restantes foram considerados de média complexidade (876 a 1161 pontos). A classificação de complexidade (baixa, média e alta) é espe-

\footnotetext{
${ }^{2}$ www.ibm.com/br-pt/marketplace/spss-statistics
} 
cífica da amostra de infográficos utilizada neste experimento, visto que a variação dos infográficos certamente resultará em valores de complexidade diferentes.

Com base na descrição do design experimental, é possível classificar a abordagem experimental como sendo um fator com três tratamentos (Montgomery, 2008). O fator é a complexidade dos infográficos e os tratamentos são: baixa, média e alta complexidade.

A Tabela 5 mostra os valores das médias e desvios padrão para as medidas de aprendizado e número de acertos. A medida "número de acertos"se refere às 45 questões presentes nos questionários de conhecimento aplicados em cada fase (Seção 5.1.2). Nosso interesse está em analisar o "número de acertos"dos testes aplicados nas Fases B e C, pois estes foram aplicados após a interação com os infográficos, logo, foram influenciados por eles. As medidas de aprendizado $\Delta 1$, $\Delta 2$ e $\Delta 3$ representam, respectivamente, o quanto um aluno aprendeu da Fase A para a Fase B, o quanto um aluno perdeu da Fase B para a Fase C, e o quanto de conteúdo foi retido da Fase A até a Fase $\mathrm{C}$ do experimento.

Tabela 5: Número de acertos e medidas de aprendizado por complexidade do Infográfico.

\begin{tabular}{|l|l|c|c|c|c|c|}
\hline & \multicolumn{9}{|c|}{$\begin{array}{l}\text { Infográficos } \\
\text { Complexidade Baixa }\end{array}$} & \multicolumn{2}{c|}{ Complexidade Média } & \multicolumn{2}{c|}{ Complexidade Alta } \\
\cline { 2 - 7 } & Média & DP & Média & DP & Média & DP \\
\hline $\begin{array}{l}\text { Número de acertos na } \\
\text { Fase A (Pré-teste) }\end{array}$ & 5,750 & 1,894 & 7,958 & 1,160 & 6,000 & 1,842 \\
\hline $\begin{array}{l}\text { Número de acertos na } \\
\text { Fase B (Pós-teste) }\end{array}$ & 13,167 & 0,963 & 11,167 & 2,099 & 10,792 & 2,734 \\
\hline $\begin{array}{l}\text { Número de acertos na } \\
\text { Fase C (Retenção) }\end{array}$ & 12,250 & 1,726 & 10,792 & 2,206 & 10,083 & 2,701 \\
\hline$\Delta 1$ Aprendizado Imediato & 7,417 & 1,954 & 3,208 & 2,187 & 4,792 & 3,148 \\
\hline$\Delta 2$ Perda & 0,917 & 1,139 & 0,375 & 1,013 & 0,708 & 1,944 \\
\hline$\Delta 3$ Retenção & 6,500 & 2,246 & 2,833 & 2,200 & 4,083 & 2,842 \\
\hline
\end{tabular}

Dentre as 45 questões que compõem cada questionário de conhecimento, 15 se referem à infográficos de uma mesma complexidade. É esperado que os alunos consigam retirar mais informações de infográficos classificados como de complexidade baixa do que de infográficos classificados como de média ou alta complexidade. As médias apresentadas na Tabela 5 são consistentes com essa afirmativa.

Assim, o número médio de acertos no grupo de questões referentes aos infográficos de complexidade baixa foi o maior dentre os três grupos, tanto na Fase B $(\mu=13,167 ; \sigma=0,963)$ como na Fase $\mathrm{C}(\mu=12,250 ; \sigma=1,726)$. Do mesmo modo, os alunos acertaram, em média, menos questões referentes aos infográficos de complexidade alta (Fase B: $\mu=10,792 ; \sigma=2,734$; Fase $\mathrm{C}: \mu=10,083 ; \sigma=2,701)$.

As medidas de aprendizado $\Delta 1$ e $\Delta 3$ também se apresentaram coerentes com a classificação de complexidade dos infográficos. Dentre os três níveis de complexidade, as maiores médias de crescimento no número de questões corretas foram para as questões referentes aos infográficos de baixa complexidade $(\Delta 1: \mu=7,417 ; \sigma=1,954$ e $\Delta 3: \mu=6,500 ; \sigma=2,246)$. Em contrapartida, a menor taxa de perda de conhecimento $(\Delta 2)$ foi para as questões referentes aos infográficos de média complexidade $(\Delta 2: \mu=0,375 ; \sigma=1,013)$ e a maior para os infográficos de baixa complexidade $(\Delta 2: \mu=0,917 ; \sigma=1,139)$, contrariando a classificação de complexidade dos 
infográficos.

Para testar o primeiro conjunto de hipóteses relacionadas à aprendizagem será utilizado o teste ANOVA que é recomendado para configurações experimentais nas quais existe um fator (complexidade) e mais de dois tratamentos (baixa, média e alta), e nas quais as métricas das variáveis dependentes (aprendizado e tempo) apresentam medidas na escala razão. A Tabela 6 mostra o resultado do teste estatístico para as medidas de aprendizagem, comparando as médias de acertos nas questões referentes aos infográficos de baixa, média e alta complexidade. É possível observar a diferença estatisticamente significativa entre as médias de aprendizagem dos três grupos de complexidade (Fase B: $F(2,69)=9,163 ; p=, 000$; Fase C: $F(2,69)=5,803 ; p=, 005 ; \Delta 1$ : $F(2,69)=17,573 ; p=, 000 ; \Delta 3: F(2,69)=13,926 ; p=, 000)$, com exceção da medida de perda de conhecimento $(\Delta 2: F(2,69)=, 880 ; p=, 419)$.

Tabela 6: Teste ANOVA para as medidas de aprendizagem considerando a complexidade dos infográficos.

\begin{tabular}{|c|c|c|c|c|c|c|}
\hline & & $\begin{array}{l}\text { Soma dos } \\
\text { Quadrados }\end{array}$ & $\begin{array}{l}\text { Graus de Li- } \\
\text { berdade }\end{array}$ & $\begin{array}{l}\text { Quadrado } \\
\text { Médio }\end{array}$ & $\mathrm{F}$ & Sig. \\
\hline \multirow{3}{*}{$\begin{array}{l}\text { Acertos na } \\
\text { Fase A }\end{array}$} & Entre grupos & 70,194 & 2 & 35,097 & 12,649 &, $000 * *$ \\
\hline & $\begin{array}{ll}\text { Dentro } & \text { dos } \\
\text { Grupos } & \end{array}$ & 191,458 & 69 & 2,775 & & \\
\hline & Total & 261,653 & 71 & & & \\
\hline \multirow{3}{*}{$\begin{array}{l}\text { Acertos na } \\
\text { Fase B }\end{array}$} & Entre grupos & 78,250 & 2 & 39,125 & 9,163 &, $000 * *$ \\
\hline & $\begin{array}{l}\text { Dentro dos } \\
\text { Grupos }\end{array}$ & 294,625 & 69 & 4,270 & & \\
\hline & Total & 372,875 & 71 & & & \\
\hline \multirow{3}{*}{$\begin{array}{l}\text { Acertos na } \\
\text { Fase } C\end{array}$} & Entre grupos & 58,583 & 2 & 29,292 & 5,803 &, $005^{* *}$ \\
\hline & $\begin{array}{l}\text { Dentro dos } \\
\text { Grupos }\end{array}$ & 348,292 & 69 & 5,048 & & \\
\hline & Total & 406,875 & 71 & & & \\
\hline \multirow{3}{*}{$\begin{array}{l}\text { Aprendizado } \\
\text { Imediato } \\
(\mathrm{B}-\mathrm{A})\end{array}$} & Entre grupos & 216,861 & 2 & 108,431 & 17,573 &, $000 * *$ \\
\hline & $\begin{array}{l}\text { Dentro dos } \\
\text { Grupos }\end{array}$ & 425,750 & 69 & 6,170 & & \\
\hline & Total & 642,611 & 71 & & & \\
\hline \multirow[t]{3}{*}{ Perda (B-C) } & Entre grupos & 3,583 & 2 & 1,792 & ,880 & ,419 \\
\hline & $\begin{array}{l}\text { Dentro dos } \\
\text { Grupos }\end{array}$ & 140,417 & 69 & 2,035 & & \\
\hline & Total & 144,000 & 71 & & & \\
\hline \multirow{3}{*}{$\begin{array}{l}\text { Retenção (C- } \\
\text { A) }\end{array}$} & Entre grupos & 166,778 & 2 & 83,389 & 13,926 &, $000 * *$ \\
\hline & $\begin{array}{ll}\text { Dentro } & \text { dos } \\
\text { Grupos } & \end{array}$ & 413,167 & 69 & 5,988 & & \\
\hline & Total & 579,944 & 71 & & & \\
\hline
\end{tabular}

Os valores significativos indicam que, dentre as médias dos três grupos analisados, ao menos duas foram consideradas estatisticamente diferentes em $95 \%$ dos casos $(p=0,05)$. No entanto, é preciso identificar quais são esses grupos. Assim, foi executado o teste de Múltiplas Comparações que é mostrado na Tabela 7 para identificar os grupos com médias significativamente diferentes, que foram marcados por asterisco $(* *)$.

Tanto para a variável aprendizado imediato, quanto para a retenção de conhecimento 
Tabela 7: Teste de Múltiplas Comparações para as medidas de aprendizagem considerando a complexidade dos infográficos.

\begin{tabular}{|c|c|c|c|c|c|}
\hline & $\begin{array}{lr}\text { (I) } & \text { Comple- } \\
\text { xidade } & \text { do } \\
\text { Infográfico }\end{array}$ & $\begin{array}{lr}(\mathrm{J}) & \text { Comple- } \\
\text { xidade } & \text { do } \\
\text { Infográfico }\end{array}$ & $\begin{array}{l}\text { Diferença Média } \\
\text { (I-J) }\end{array}$ & Erro padrão & Sig. \\
\hline \multirow{6}{*}{$\begin{array}{l}\text { Acertos } \\
\text { na } \\
\text { Fase A }\end{array}$} & \multirow[t]{2}{*}{ Baixa } & Média & $-2,208^{*}$ &, 481 &, $000 * *$ \\
\hline & & Alta &,- 250 & ,481 &, 862 \\
\hline & \multirow[t]{2}{*}{ Média } & Baixa & $2,208^{*}$ & ,481 &, $000^{* *}$ \\
\hline & & Alta & $1,958^{*}$ &, 481 &, $000^{* * *}$ \\
\hline & \multirow[t]{2}{*}{ Alta } & Baixa &, 250 & ,481 & 862 \\
\hline & & Média & $-1,958^{*}$ &, 481 &, $000^{* * *}$ \\
\hline \multirow{6}{*}{$\begin{array}{l}\text { Acertos } \\
\text { na } \\
\text { Fase B }\end{array}$} & \multirow[t]{2}{*}{ Baixa } & Média & $2,000^{*}$ & ,597 &, $004 * *$ \\
\hline & & Alta & $2,375^{*}$ & ,597 &, $000 * *$ \\
\hline & \multirow[t]{2}{*}{ Média } & Baixa & $-2,000^{*}$ & ,597 &, $004 * *$ \\
\hline & & Alta & ,375 & ,597 & 805 \\
\hline & \multirow[t]{2}{*}{ Alta } & Baixa & $-2,375^{*}$ &, 597 &, $000^{* *}$ \\
\hline & & Média &,- 375 & ,597 & 805 \\
\hline \multirow{6}{*}{$\begin{array}{l}\text { Acertos } \\
\text { na } \\
\text { Fase C }\end{array}$} & \multirow[t]{2}{*}{ Baixa } & Média & 1,458 & ,649 & ,070 \\
\hline & & Alta & $2,167^{*}$ & ,649 &, $004 * *$ \\
\hline & \multirow[t]{2}{*}{ Média } & Baixa & $-1,458$ & ,649 &, 070 \\
\hline & & Alta &, 708 & ,649 &, 522 \\
\hline & \multirow[t]{2}{*}{ Alta } & Baixa & $-2,167 *$ & ,649 &, $004 * *$ \\
\hline & & Média &,- 708 & ,649 &, 522 \\
\hline \multirow{6}{*}{$\begin{array}{l}\text { Aprendizado } \\
\text { Imediato } \\
\text { (B-A) }\end{array}$} & \multirow[t]{2}{*}{ Baixa } & Média & $4,20833^{*}$ & ,71707 &, $000^{* *}$ \\
\hline & & Alta & $2,62500^{*}$ & ,71707 &, $001^{* *}$ \\
\hline & \multirow[t]{2}{*}{ Média } & Baixa & $-4,20833^{*}$ & ,71707 &, $000^{* *}$ \\
\hline & & Alta & $-1,58333$ &, 71707 & ,077 \\
\hline & \multirow[t]{2}{*}{ Alta } & Baixa & $-2,62500^{*}$ & ,71707 &, $001^{* *}$ \\
\hline & & Média & 1,58333 &, 71707 &, 077 \\
\hline \multirow[t]{6}{*}{ Perda (B-C) } & \multirow[t]{2}{*}{ Baixa } & Média & ,54167 & ,41181 & ,392 \\
\hline & & Alta & 20833 & ,41181 &, 869 \\
\hline & \multirow[t]{2}{*}{ Média } & Baixa &,- 54167 & ,41181 & ,392 \\
\hline & & Alta &,- 33333 & ,41181 & ,698 \\
\hline & \multirow[t]{2}{*}{ Alta } & Baixa &,- 20833 &, 41181 & ,869 \\
\hline & & Média & ,33333 & ,41181 & 698 \\
\hline \multirow[t]{6}{*}{ Retenção (C-A) } & \multirow[t]{2}{*}{ Baixa } & Média & $3,66667 *$ &, 70639 &, $000 * *$ \\
\hline & & Alta & $2,41667^{*}$ & ,70639 &, $003^{* *}$ \\
\hline & \multirow{2}{*}{ Média } & Baixa & $-3,66667^{*}$ & ,70639 &, $000^{* *}$ \\
\hline & & Alta & $-1,25000$ & ,70639 & , 187 \\
\hline & \multirow[t]{2}{*}{ Alta } & Baixa & $-2,41667^{*}$ & ,70639 &, $003^{* *}$ \\
\hline & & Média & 1,25000 & ,70639 & , 187 \\
\hline
\end{tabular}

existe diferença significativa entre as médias dos infográficos de complexidade baixa e média $(\Delta 1: p=, 000 ; \Delta 3: p=, 000)$ e baixa e alta $(\Delta 1: p=, 001 ; \Delta 3: p=, 003)$. Porém, a diferença entre as médias referentes às complexidades média e alta não foram estatisticamente significativas nas mesmas duas medidas $(\Delta 1: p=, 077 ; \Delta 3: p=, 187)$. Por meio da estatística descritiva, podemos observar que a média de aprendizado imediato e retenção foi mais alta para os infográficos de baixa complexidade $(\Delta 1: \mu=7,417 ; \sigma=1,954$ e $\Delta 3: \mu=6,500 ; \sigma=2,246)$, em outras palavras, os alunos aprenderam significativamente mais a partir de infográficos de baixa complexidade.

Em suma, as médias de perda de conhecimento $(\Delta 2)$ para as três complexidades não são 
estatisticamente diferentes, sendo aceita a hipótese nula (HO: Não existe diferença entre a perda de conhecimento $(\Delta 2)$ por meio de infográficos com baixa, média ou alta complexidade) para essa medida. No entanto, considerando as medidas aprendizado imediato $(\Delta 1)$ e retenção de conhecimento $(\Delta 3)$, a hipótese nula é refutada fazendo com que a hipótese alternativa seja aceita (H1: Existe diferença entre o aprendizado imediato e a retenção de conhecimento ( $\Delta 1$ e $\Delta 3)$ por meio de infográficos com baixa, média e alta complexidade).

Desse modo, podemos afirmar que houve influência da complexidade do infográfico no aprendizado apenas quando essa complexidade foi dada como baixa. Os alunos obtiveram maior aprendizado imediato e retenção de conhecimento a partir dos cinco infográficos de complexidade baixa, do que a partir dos infográficos de complexidade média e alta. A partir desses resultados é possível inferir que o framework para classificação da complexidade dos infográficos foi correto quanto à classificação da complexidade baixa, mas necessita ser calibrado quanto à classificação das complexidades média e alta. Outra interpretação possível está ligada a capacidade do formato infográfico de resumir e simplificar informações complexas. Assim, podemos concluir que a partir de um determinado nível de complexidade, a natureza explicativa do infográfico permite que o aprendizado do aluno seja estável, mesmo que essa complexidade aumente.

A variável tempo médio de visualização também foi utilizada para avaliar a classificação da complexidade dos infográficos de acordo com o framework. Espera-se que infográficos de complexidade baixa levem menos tempo para serem lidos. Com efeito, os infográficos classificados como de baixa complexidade, apresentaram a menor média de tempo gasto pelos alunos $(\mu=49,180 s ; \sigma=26,131 s)$. Ao mesmo tempo, a média de tempo aumenta acompanhando o aumento da complexidade para média $(\mu=88,099 s ; \sigma=58,640 s)$ e alta $(\mu=140,539 s$; $\sigma=91,051 s)$.

Para verificar se essa diferença nas médias de tempo é significativa também foi utilizado o teste ANOVA. A Tabela 8 mostra o resultado do teste e confirma uma diferença estatisticamente significativa entre as médias $(F(2,357)=60,964 ; p=, 000)$. Para identificar quais dentre os três grupos têm médias significativamente diferentes foi executado o teste de Múltiplas Comparações, exibido na Tabela 9. O teste mostra que tanto a média de tempo nos infográficos de baixa complexidade como a média de tempo nos infográficos de média e de alta complexidade diferem significativamente entre si $(p=, 000)$.

Com esses resultados, é possível confirmar a diferença entre as médias, aceitando a hipótese alternativa de que existe diferença entre o tempo gasto em infográficos de complexidade baixa, média e alta.

Tabela 8: Teste ANOVA para as medidas de tempo entre as complexidades dos infográficos.

\begin{tabular}{|l|l|l|l|l|l|}
\hline & $\begin{array}{l}\text { Soma dos } \\
\text { Quadrados }\end{array}$ & $\begin{array}{l}\text { Graus de Li- } \\
\text { berdade }\end{array}$ & $\begin{array}{l}\text { Quadrado } \\
\text { Médio }\end{array}$ & F & Sig. \\
\hline Entre grupos & 3,686 & 2 & 1,843 &, 452 &, 641 \\
\hline $\begin{array}{l}\text { Dentro dos } \\
\text { Grupos }\end{array}$ & 101,942 & 25 & 4,078 & & \\
\hline Total & 105,627 & 27 & & & \\
\hline
\end{tabular}

Por fim, considerando o objetivo geral do experimento foi possível obter evidências de que a complexidade calculada pelo framework tem relação com a real complexidade do infográfico. 
Tabela 9: Teste de Múltiplas Comparações para as medidas de tempo entre as complexidades dos infográficos.

\begin{tabular}{|l|l|l|l|l|}
\hline $\begin{array}{l}\text { (I) Complexidade do } \\
\text { Infográfico }\end{array}$ & $\begin{array}{l}\text { (J) Complexidade do } \\
\text { Infográfico }\end{array}$ & $\begin{array}{l}\text { Diferença Mé- } \\
\text { dia (I-J) }\end{array}$ & $\begin{array}{l}\text { Erro } \\
\text { padrão }\end{array}$ & Sig. \\
\hline \multirow{2}{*}{ Baixa } & Média & $-38,919^{* *}$ & 8,304 &, 000 \\
\cline { 2 - 5 } & Alta & $-91,360^{* *}$ & 8,304 &, 000 \\
\hline \multirow{2}{*}{ Média } & Baixa & $38,919^{* *}$ & 8,304 &, 000 \\
\cline { 2 - 5 } & Alta & $-52,441^{* *}$ & 8,304 &, 000 \\
\hline \multirow{2}{*}{ Alta } & Baixa & $91,360^{* *}$ & 8,304 &, 000 \\
\cline { 2 - 5 } & Média & $52,441^{* *}$ & 8,304 &, 000 \\
\hline
\end{tabular}

Analisando os resultados para as variáveis aprendizado e tempo, verificou-se que, de fato, infográficos classificados como de baixa complexidade pelo framework proporcionam maior aprendizagem em menor tempo de visualização. No entanto, o aprendizado por meio dos infográficos de complexidade alta não foi significativamente menor. É possível atribuir essa queda não significativa à natureza explicativa dos infográficos, capaz de estabilizar o aprendizado do aluno a partir de um determinado nível de complexidade, mesmo que a complexidade aumente(K. Lyra \& Isotani, 2017). Ainda, é preciso considerar a necessidade de ajustar às métricas utilizadas no framework para a classificação das complexidades média e alta.

\section{Conclusão}

O constante desenvolvimento e uso de ambientes virtuais de aprendizagem como MOOCs e Sistemas Tutores Inteligentes faz com que os professores e desenvolvedores desses ambientes precisem avaliar qual formato de visualização a ser utilizado. Para isso, é importante entender o impacto de cada tipo de material nos diversos aspectos do processo de ensino-aprendizagem.

A principal contribuição deste trabalho foi a proposição de um framework para analisar e classificar a complexidade de visualizações do tipo infográfico. Até o presente momento não se tem conhecimento na literatura de nenhum outro framework para classificação da complexidade dos infográficos, como o proposto neste estudo.

A avaliação realizada buscou verificar se a complexidade calculada pelo framework está de acordo com a real complexidade do infográfico. Baseado no conceito de carga cognitiva, foi realizado um experimento controlado para testar a hipótese de que alunos gastam menos tempo e aprendem mais por meio de infográficos de complexidade mais baixa. As análises mostraram que o aprendizado foi significativamente maior para infográficos menos complexos em comparação com infográficos mais complexos.

Como contribuição à comunidade científica, este trabalho deixa assertivas sobre o impacto e uso adequado do formato de material de aprendizagem conhecido como infográfico. Além disso, foram disponibilizados todos os instrumentos desenvolvidos e utilizados, os dados coletados, e as análises realizadas com o objetivo de atenuar a carência de resultados empíricos sobre o uso de infográficos no aprendizado e incentivar a comunidade a divulgar seus resultados de forma pública e aberta. Os materiais e resultados podem ser encontrados no LabPackage do experimento 
em http://kamilalyra.github.io/Experimento-Infograficos/index.html.

A classificação de complexidade, juntamente com o fato de o aprendizado não ser significativamente menor para infográficos de complexidade alta, devem ser considerados na tomada de decisão sobre quando é viável ou não gerar uma visualização para transmitir um conteúdo. Além de medir a complexidade, as dimensões avaliadas pelo framework podem servir como parâmetro para que desenvolvedores de infográficos aumentem ou diminuam a complexidade de seus materiais.

Espera-se que as contribuições aqui apresentadas possam ser aplicadas tanto de modo informal, por professores e alunos no dia a dia do aprendizado, como de modo formal, por desenvolvedores de materiais e de ambientes virtuais de aprendizagem, com o objetivo de tornar o processo de aprendizagem mais efetivo.

\section{Agradecimentos}

Os autores agradecem ao CNPq, CAPES e FAPESP pelo apoio financeiro durante a execução desse trabalho.

\section{References}

Albers, M. J. (2014). Infographics: Horrid chartjunk or quality communication. In Professional communication conference (ipcc) (pp. 1-4). Pittsburgh, PA, USA: IEEE. doi: 10.1109/IPCC.2014.7020344 [GS Search]

Albers, M. J. (2015). Infographics and communicating complex information. In International conference of design, user experience, and usability (pp. 267-276). Los Angeles, CA, USA: Springer, Cham. doi: 10.1007/978-3-319-20898-5_26 [GS Search]

Andrews, G., \& Halford, G. S. (2002). A cognitive complexity metric applied to cognitive development. Cognitive Psychology, 45(2), 153-219. doi: 10.1016/S0010-0285(02)000026 [GS Search]

Andrews, G., Halford, G. S., Bunch, K. M., Bowden, D., \& Jones, T. (2003). Theory of mind and relational complexity. Child development, 74(5), 1476-1499. doi: 10.1111/14678624.00618 [GS Search]

Baddeley, A. (1994). The magical number seven: Still magic after all these years? Psychological Review, 101(2), 353-356. doi: 10.1037/0033-295X.101.2.353 [GS Search]

Bertin, J. (2011). Semiology of graphics: Diagrams, networks, maps. ESRI Press. [GS Search]

Brehmer, M., \& Munzner, T. (2013). A multi-level typology of abstract visualization tasks. IEEE Transactions on Visualization and Computer Graphics, 19(12), 2376-2385. doi: 10.1109/TVCG.2013.124 [GS Search]

Burkhard, R. A. (2004). Learning from architects: the difference between knowledge visualization and information visualization. In Proceedings. eighth international conference on information visualisation, 2004. iv 2004. (p. 519-524). doi: 10.1109/IV.2004.1320194 [GS Search] 
Card, S. K., Mackinlay, J. D., \& Shneiderman, B. (1999). Readings in information visualization: using vision to think. San Francisco, CA, USA: Morgan Kaufmann Publishers Inc. [GS Search]

Carr, D. (1999). Guidelines for designing information visualization applications. In Proceedings of the ericsson conference on usability engineering ecue (pp. 1-3). Stockholm, Sweden. [GS Search]

Chen, C. (2005). Top 10 unsolved information visualization problems. IEEE Computer Graphics and Applications, 25(4), 12-16. doi: 10.1109/MCG.2005.91 [GS Search]

Clark, R., Nguyen, F., \& Sweller, J. (2011). Efficiency in learning: Evidence-based guidelines to manage cognitive load. John Wiley \& Sons. [GS Search]

Cleveland, W. S. (1994). The elements of graphing data. AT\&T Bell Laboratories. [GS Search]

Collins-Thompson, K., \& Callan, J. (2004). A language modeling approach to predicting reading difficulty. In Proceedings of the Human Language Technology Conference of the North American Chapter of the Association for Computational Linguistics: HLT-NAACL 2004.. [GS Search]

Cowan, N. (2010). The magical mystery four: How is working memory capacity limited, and why? Current directions in psychological science, 19(1), 51-57. doi: 10.1177/0963721409359277 [GS Search]

Cox, R. (1999). Representation construction, externalised cognition and individual differences. Learning and Instruction, 9(4), 343-363. doi: 10.1016/S0959-4752(98)00051-6 [GS Search]

Cuevas, H. M., Fiore, S. M., \& Oser, R. L. (2002). Scaffolding cognitive and metacognitive processes in low verbal ability learners: Use of diagrams in computer-based training environments. Instructional Science, 30(6), 433-464. doi: 10.1023/A:1020516301541 [GS Search]

Dale, E., \& Chall, J. S. (1948). A formula for predicting readability: Instructions. Educational Research Bulletin, 27(2), 37-54. Retrieved from http://www.jstor.org/stable/1473669 [GS Search]

Diakopoulos, N., Kivran-swaine, F., \& Naaman, M. (2011, may). Playable data : Characterizing the design space of game-y infographics. In Acm chi conference on human factors in computing systems (pp. 1717-1726). Vancouver, BC, Canada: ACM. doi: 10.1145/1978942.1979193 [GS Search]

Figueiras, A. (2013, July). A typology for data visualization on the web. In Information visualization (iv), 2013 17th international conference (pp. 351-358). London, UK: IEEE. doi: 10.1109/IV.2013.45 [GS Search]

Flesch, R. (1948). A new readability yardstick. Journal of Applied Psychology, 32(3), 221. doi: 10.1037/h0057532 [GS Search]

Freitas, C. M. D. S., Chubachi, O. M., Luzzardi, P. R. G., \& Cava, R. A. (2001). Introdução à visualização de informações. Revista de Informática Teórica e Aplicada, 8(2), 143-158. [GS Search]

Fry, E. (1968). A readability formula that saves time. Journal of Reading, 11(7), 513-578. [GS Search]

Gärtner, J., Miksch, S., \& Carl-McGrath, S. (2002, April). Vico: a metric for the complexity of information visualizations. In International conference on theory and application of diagrams (pp. 249-263). Callaway Gardens, GA, USA: Springer, Berlin, Heidelberg. 
Gerber, R., Boulton-Lewis, G., \& Bruce, C. (1995). Children's understanding of graphic representations of quantitative data. Learning and Instruction, 5(1), 77-100. [GS Search]

Gyselinck, V., \& Tardieu, H. (1999). The role of illustrations in text comprehension: what, when, for whom, and why? Lawrence Erlbaum Associates Publishers, 195-218. [GS Search]

Halford, G. S., Andrews, G., \& Jensen, I. (1998). Category induction and hierarchical classification assessed by property inference: The influence of complexity. ERIC. [GS Search]

Halford, G. S., Wilson, W. H., \& Phillips, S. (1998). Processing capacity defined by relational complexity: implications for comparative, developmental, and cognitive psychology. The Behavioral and brain sciences, 21(6), 803-831; discussion 831-864. doi: 10.1017/S0140525X98001769 [GS Search]

Hegarty, M., Carpenter, P. A., \& Just, M. A. (1991). Diagrams in the comprehension of scientific texts. , 2, 641-668. [GS Search]

Jonassen, D. H., Reeves, T. C., Hong, N., Harvey, D., \& Peters, K. (1997). Concept mapping as cognitive learning and assessment tools. Journal of interactive learning research, 8(3), 289. [GS Search]

Kincaid, J. P., Fishburne Jr, R. P., Rogers, R. L., \& Chissom, B. S. (1975). Derivation of new readability formulas (automated readability index, fog count and flesch reading ease formula) for navy enlisted personnel. Institute for Simulation and Training, University of Central Florida. [GS Search]

King, D. B., \& Wertheimer, M. (2005). Max wertheimer and gestalt theory. Transaction Publishers. [GS Search]

Larkin, J. H., \& Simon, H. A. (1987). Why a diagram is (sometimes) worth ten thousand words. Cognitive Science, 11(1), 65 - 100. doi: 10.1016/S0364-0213(87)80026-5 [GS Search]

Lee, E.-J., \& Kim, Y. W. (2016). Effects of infographics on news elaboration, acquisition, and evaluation: Prior knowledge and issue involvement as moderators. New Media \& Society, 18(8), 1579-1598. doi: 10.1177/1461444814567982 [GS Search]

Leturia, E. (1998). ¿ qué es infografía. Revista Latina de Comunicación Social, 4(10). [GS Search]

Lyra, K., \& Isotani, S. (2017). Impacto do uso de infográficos como materiais de aprendizagem e suas correlações com satisfação, estilos de aprendizagem e complexidade visual. In Anais dos workshops do congresso brasileiro de informática na educação (cbie) (Vol. 6, p. 46). doi: 10.5753/cbie.wcbie.2017.46 [GS Search]

Lyra, K. T. (2017, 4). Impacto do uso de infográficos como materiais de aprendizagem e suas correlações com satisfação, estilos de aprendizagem e complexidade visual. Dissertação de Mestrado. Instituto de Ciências Matemáticas e de Computação - Universidade de São Paulo. doi: 10.11606/D.55.2017.tde-02082017-104605 [GS Search]

Lyra, K. T., Isotani, S., Reis, R. C. D., Marques, L. B., Pedro, L. Z., Jaques, P. A., \& Bitencourt, I. I. (2016, July). Infographics or graphics+text: Which material is best for robust learning? In 2016 ieee 16th international conference on advanced learning technologies (icalt) (p. 366-370). doi: 10.1109/ICALT.2016.83 [GS Search]

Lyra, K. T., Oliveira, B. R., Reis, R. C., Cruz, W. M., Nakagawa, E. Y., \& Isotani, S. (2016). Infográficos versus materiais de aprendizagem tradicionais: uma investigação empírica. $R E-$ NOTE - Revista Novas Tecnologias na Educação, 14(2). doi: 10.22456/1679-1916.70653 [GS Search]

Machado, V., Margarida, L., \& Tarouco, R. (2010). Infográfico : características , autoria e uso 
educacional. Novas Tecnologias na Educação, 8(3). [GS Search]

Martins, T. B. F., Ghiraldelo, C. M., Nunes, M. G. V., \& Júnior, O. N. O. (1996). Readability Formulas Applied to Textbooks in Brazilian Portuguese. Notas do ICMSC-USP ICMC. [GS Search]

Masud, L., Valsecchi, F., Ciuccarelli, P., Ricci, D., \& Caviglia, G. (2010). From data to knowledge: Visualizations as transformation processes within the data-information-knowledge continuum. Proceedings of the International Conference on Information Visualisation, 445449. doi: 10.1109/IV.2010.68 [GS Search]

Mayer, R. E. (2003). The promise of multimedia learning: using the same instructional design methods across different media. Learning and instruction, 13(2), 125-139. doi: 10.1016/S0959-4752(02)00016-6 [GS Search]

Mayer, R. E., Bove, W., Bryman, A., Mars, R., \& Tapangco, L. (1996). When less is more: Meaningful learning from visual and verbal summaries of science textbook lessons. Journal of educational psychology, 88(1), 64. [GS Search]

McCormick, B. H., DeFanti, T. A., \& Brown, M. D. (1987). Visualization in scientific computing. IEEE Computer Graphics and Applications, 7(10), 69-69. [GS Search]

McLoud, S. (2000). Reinventing comics: How imagination and technology are revolutionizing an art form. Perennial, New York, 118-122. [GS Search]

MIT News (1996, Dec). Mit research - brain processing of visual information. Author. Retrieved from http://news.mit.edu/1996/visualprocessing

Montgomery, D. C. (2008). Design and analysis of experiments. John Wiley \& Sons. [GS Search] Naps, T., Cooper, S., Koldehofe, B., Leska, C., Rößling, G., Dann, W., ... McNally, M. (2003). Evaluating the educational impact of visualization. In Acm sigcse bulletin (Vol. 35, pp. 124-136). [GS Search]

Paas, F., Renkl, A., \& Sweller, J. (2004). Cognitive load theory: Instructional implications of the interaction between information structures and cognitive architecture. Instructional science, 32(1-2), 1-8. [GS Search]

Ribas, B. (2004). Infografia multimídia: um modelo narrativo para o webjornalismo. Anais do II SBPJor (CD-ROM). Salvador-BA/Brasil. [GS Search]

Risch, J. S. (2008). On the role of metaphor in information visualization. arXiv preprint arXiv:0809.0884, 20. [GS Search]

Schwarm, S. E., \& Ostendorf, M. (2005). Reading Level Assessment Using Support Vector Machines and Statistical Language Models. Annual Meeting of the Association for Computational Linguistics(June), 523-530. doi: 10.3115/1219840.1219905 [GS Search]

Sebrechts, M. M. (2005). Visualizing information in virtual space: Prospects and pitfalls. In Knowledge and information visualization (pp. 136-166). Springer. [GS Search]

Smiciklas, M. (2012). The power of infographics: Using pictures to communicate and connect with your audiences. Que Publishing. doi: 10.4324/9780203075609 [GS Search]

Stenner, A. J. (1996). Measuring reading comprehension with the lexile framework. ERIC. [GS Search]

Sweller, J. (1988). Cognitive load during problem solving: Effects on learning. Cognitive Science, 12(2), 257-285. doi: 10.1016/0364-0213(88)90023-7 [GS Search]

Sweller, J., Van Merrienboer, J. J., \& Paas, F. G. (1998). Cognitive architecture and instructional design. Educational psychology review, 10(3), 251-296. [GS Search] 
Toth, C. (2013). Revisiting a Genre: Teaching Infographics in Business and Professional Communication Courses. Business Communication Quarterly, 76(4), 446-457. doi: 10.1177/1080569913506253 [GS Search]

Van Merrienboer, J. J., \& Sweller, J. (2005). Cognitive load theory and complex learning: Recent developments and future directions. Educational psychology review, 17(2), 147-177. [GS Search]

Van Merriënboer, J. J., \& Sweller, J. (2010). Cognitive load theory in health professional education: design principles and strategies. Medical education, 44(1), 85-93. [GS Search]

Wohlin, C., Runeson, P., Höst, M., Ohlsson, M. C., Regnell, B., \& Wesslén, A. (2012). Experimentation in software engineering. Springer Science \& Business Media. [GS Search]

Wolfe, J. M., \& Horowitz, T. S. (2004). What attributes guide the deployment of visual attention and how do they do it? Nature reviews neuroscience, 5(6), 495-501. [GS Search]

Zhang-Kennedy, L., Chiasson, S., \& Biddle, R. (2013, sep). Password advice shouldn't be boring: Visualizing password guessing attacks. 2013 APWG eCrime Researchers Summit, 1-11. doi: 10.1109/eCRS.2013.6805770 [GS Search]

Zhu, Y. (2007). Measuring effective data visualization. In G. Bebis et al. (Eds.), Advances in visual computing (pp. 652-661). Berlin, Heidelberg: Springer Berlin Heidelberg. [GS Search]

Zhu, Y., Suo, X., \& Owen, G. S. (2007). Complexity analysis for information visualization design and evaluation. In G. Bebis et al. (Eds.), Advances in visual computing (pp. 576-585). Berlin, Heidelberg: Springer Berlin Heidelberg. [GS Search] 